\title{
Pre-flood inundation mapping for flood early warning.
}

\begin{abstract}
In this study the results of two rainfall-run-off simulations were used as input into a MIKE11GIS and hydrological modelling process for flood inundation mapping based on the flood event (27 September to 8 October 2000) in Malaysia of the Langat River Basin area. Separate inundation maps were generated for the recorded observed rainfall and from a developed quantitative precipitation forecast (QPF), which was based on top of the cloud reflectance and brightness temperature (TB) derive from Advanced Very High Resolution Radiometer (AVHRR) and Geostationary Meteorological Satellite (GMS) satellite data sets. The QPF had rain rates between 3 and $12 \mathrm{~mm} / \mathrm{h}$ for the $264 \mathrm{~h}$ rainfall duration. While the actual recorded rainfall for the same duration was used for the observed. The objective of the study was to compare the similarities of the flood inundation generated from the QPF run-off with that generated from the rainfall-run-off of the actual flood event. The accuracies of the maps were verified using grid point locations of flooded areas taken during the event. The selected sampled point of the verification showed an accuracy of $70 \%$ of the QPF on the observed flood map. Sampled points measured flood extent, coverage and depth of flood in the basin area.
\end{abstract}

Keyword: Flood warning; Hydrological GIS modelling; Langat River Basin; Malaysia; Mapping; pre-flood inundation; Rainfall-run-off simulation 